\title{
Cost optimization of composite floors
}

\author{
S. Kravanja \& U. Klanšek \\ University of Maribor, Faculty of Civil Engineering, \\ Smetanova 17, 2000 Maribor, Slovenia
}

\begin{abstract}
The paper presents the cost optimization of composite floors. The composite structure consists of a reinforced concrete slab and welded steel Pratt trusses built up of hot rolled channel sections. The structural optimization is performed by the nonlinear programming (NLP) approach taking into account design constraints defined according to Eurocodes. A detailed objective function of the manufacturing material, power and labour costs is subjected to structural analysis constraints. In this way, the obtained optimal structural design satisfied the conditions of both the ultimate and the serviceability limit states. An example of the optimization of the composite truss floor system is presented at the end of the paper in order to show the applicability of the proposed approach.
\end{abstract}

Keywords: structural optimization, non-linear programming, composite structures, costs.

\section{Introduction}

The economy of construction is commonly handled in engineering practice by the time-consuming structural analysis of various design alternatives. In the conceptual design stage, the costs related with a change in the structural design are low. The possibilities of such a change to decrease (or increase) the costs in the construction stage are numerous. Since the significant cost savings may be obtained on account of effective conceptual design, the importance of accurate structural cost optimization cannot be overemphasized.

Over the last three decades, researches and engineers have mainly considered the cost optimization of composite structures from the viewpoint of the development and application of different optimization techniques [1-4]. Majority of the performed research works include simplified cost objective functions with fixed cost parameters. 
The paper presents the cost optimization of composite floor system. The composite structure consists of a reinforced concrete slab and welded steel Pratt trusses built up of hot rolled channel sections. The optimization is performed by the nonlinear programming approach, NLP. A detailed objective function of the manufacturing material, power and labour costs is defined for the optimization, Klanšek and Kravanja [5]. The cost objective function is subjected to structural analysis constraints. The design constraints are defined according to Eurocodes $1,2,3$ and 4 [6-9] to satisfy the conditions of both the ultimate (ULS) and the serviceability (SLS) limit states. An example of the optimization of the composite truss floor is presented at the end of the paper in order to show the applicability of the proposed approach.

\section{Composite trusses}

The composite floor structure is constructed of a reinforced concrete slab and welded steel Pratt trusses consisting of hot rolled channel sections, see Figure 1.

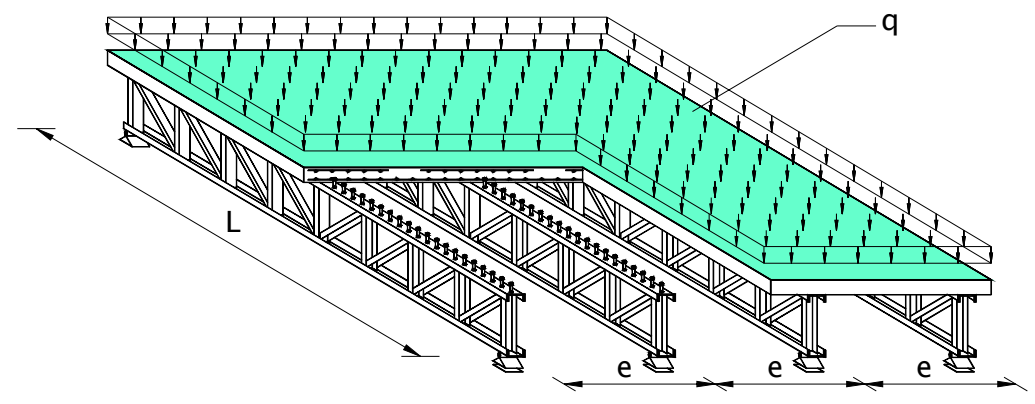

Figure 1: $\quad$ Composite trusses.

The full composite action between the concrete slab and the steel truss is achieved by the cylindrical shear studs, welded to the top chord of truss and embedded in concrete. The composite structure is designed according to Eurocode 4 [9] for both the ULS and the SLS conditions. The design loads are calculated with regard to Eurocode 1 [6]. The continuous spanning concrete slab is designed in view of Eurocode 2 [7]. The steel members are designed according to Eurocode 3 [8].

\section{NLP optimization}

\subsection{NLP problem formulation}

The structural optimization is performed by the nonlinear programming approach, NLP. The general NLP optimization problem is formulated as:

Min $z=f(\boldsymbol{x})$

subjected to:

$$
\boldsymbol{h}(\boldsymbol{x})=0
$$




$$
\boldsymbol{x} \in \boldsymbol{X}=\left\{\begin{array}{c}
\boldsymbol{g}(\boldsymbol{x}) \leq 0 \\
\left.\boldsymbol{x} \in \boldsymbol{R}^{n}, \boldsymbol{x}^{L O} \leq \boldsymbol{x} \leq \boldsymbol{x}^{U P}\right\}
\end{array}\right.
$$

where $\boldsymbol{x}$ is the vector of the continuous variables, defined within the compact set $\boldsymbol{X}$. Functions $f(\boldsymbol{x}), \boldsymbol{h}(\boldsymbol{x})$ and $\boldsymbol{g}(\boldsymbol{x})$ are the (non)linear functions involved in the objective function $z$, the equality and inequality constraints, respectively. All the functions $f(\boldsymbol{x}), \boldsymbol{h}(\boldsymbol{x})$ and $\boldsymbol{g}(\boldsymbol{x})$ must be continuous and differentiable.

In view of the optimization of composite trusses, the continuous variables define dimensions, forces, stresses, strains, cost parameters, etc. The (in)equality constraints and the bounds of the variables represent a rigorous system of design, load, resistance and deflection functions known from the structural analysis. The objective function is proposed to minimize the structure's manufacturing costs.

\subsection{Cost objective function}

The optimal design of composite trusses is determined by the minimum of the manufacturing costs. In this way, the cost objective function is defined as:

$$
\begin{aligned}
\min : \operatorname{Cos} t=\{ & C_{M, s, c, r}+C_{M, s c}+\sum_{i, j} C_{M, e_{i, j}}+\sum_{i, j} C_{M, a c, f p, t c_{i, j}}+C_{M, f} \\
& +\sum_{i, j} C_{P, c, h s_{i, j}}+\sum_{i, j} C_{P, c, g m_{i, j}}+\sum_{i, j} C_{P, w_{i, j}}+C_{P, s w}+C_{P, v} \\
& +\sum_{i, j} C_{L, c, h s_{i, j}}+\sum_{i, j} C_{L, g_{i, j}}+C_{L, p, a, t}+\sum_{i, j} C_{L, S M A W_{i, j}}+C_{L, s w} \\
& \left.+\sum_{i, j} C_{L, s p p_{i, j}}+C_{L, f}+C_{L, r}+C_{L, c}+C_{L, v}+C_{L, c c}\right\} /(e \cdot L)
\end{aligned}
$$

where Cost $\left[€ / \mathrm{m}^{2}\right]$ represents the manufacturing costs per $\mathrm{m}^{2}$ of the useable surface; $C_{M, \ldots}, C_{P, \ldots}$ and $C_{L, \ldots}$ are the material, power and labour cost items calculated in $€ ; \sum_{i, j}$ is the sum of all the truss element cost contributions; subscripts $i, j$ are the end joints of a single truss member; $e[\mathrm{~m}]$ is the intermediate distance between the trusses and $L[\mathrm{~m}]$ is the span of the composite truss. The material, power and labour costs are defined in the next equations.

\subsubsection{Material costs}

Steel, concrete and reinforcement:

$$
C_{M, s, c, r}=c_{M, s} \cdot \rho_{s} \cdot \sum_{i, j} A_{i, j} \cdot l_{i, j}+c_{M, c} \cdot d \cdot e \cdot L+c_{M, r} \cdot \rho_{s} \cdot A_{s} \cdot l_{s} \cdot L
$$

where $c_{M, s}[€ / \mathrm{kg}], c_{M, c}\left[€ / \mathrm{m}^{3}\right]$ and $c_{M, r}[€ / \mathrm{kg}]$ are the prices of the structural steel, the concrete and the reinforcement; $\rho_{s}$ is the steel density $7850 \mathrm{~kg} / \mathrm{m}^{3} ; A_{i, j}\left[\mathrm{~m}^{2}\right]$ and $l_{i, j}[\mathrm{~m}]$ are the cross-section area and the length of a single truss member; $d$ $[\mathrm{m}]$ is the depth of the concrete slab; $A_{s}\left[\mathrm{~m}^{2} / \mathrm{m}^{1}\right]$ is the cross-section area of steel reinforcement per $\mathrm{m}^{1}$ and $l_{s}[\mathrm{~m}]$ is the length of the reinforcing steel.

Cylindrical shear studs:

$$
C_{M, s c}=c_{M, s c} \cdot n_{s c}
$$

where $c_{M, s c}[€ /$ stud $]$ and $n_{s c}$ are the price and the number of cylindrical studs.

Electrode consumption, see Creese et al. [10]:

$$
C_{M, e_{i, j}}=c_{M, e} \cdot \rho_{s} \cdot A_{w_{i, j}} \cdot l_{w_{i, j}} / E M Y
$$


where $c_{M, e}[€ / \mathrm{kg}]$ is the price of the electrodes; $A w_{i, j}\left[\mathrm{~m}^{2}\right]$ is the weld crosssection area; $E M Y$ is the electrode metal yield and $l w_{i, j}[\mathrm{~m}]$ is the weld length.

Anti-corrosion, fire protection and top coat paint:

$$
C_{M, a c, f p, t c_{i, j}}=\left(c_{M, a c}+c_{M, f p}+c_{M, t c}\right) \cdot\left(1+k_{p} \cdot k_{s u r} \cdot k_{w c}\right) \cdot A_{s s_{i}, j}
$$

where $c_{M, a c}\left[€ / \mathrm{m}^{2}\right], c_{M, f p}\left[€ / \mathrm{m}^{2}\right]$ and $c_{M, t c}\left[€ / \mathrm{m}^{2}\right]$ are the prices of the anticorrosion, the fire protection and the top coat paints per $\mathrm{m}^{2}$ of painted surface; $k_{p}$, $k_{s u r}$ and $k_{w c}$ are the paint loss factors which consider the painting technique, the complexity of the structure's surface and the weather conditions in which the structure is painted; $A s s_{i, j}\left[\mathrm{~m}^{2}\right]$ is the steel surface area of the truss member.

Formwork floor-slab panels:

$$
C_{M, f}=c_{M, f} \cdot e \cdot L / n_{u c}
$$

where $c_{M, f}\left[€ / \mathrm{m}^{2}\right]$ is the price of the formwork floor-slab panels per $\mathrm{m}^{2}$ of the concrete slab panelling surface area and $n_{u c}$ is the number, how many times the formwork panels may be used before they have to be replaced with the new ones.

\subsubsection{Power costs}

Sawing the steel section:

$$
C_{P, c, h s, j}=c_{P} \cdot\left(P_{h s} / \eta_{h s}\right) \cdot k_{a m} \cdot T_{c, h s} \cdot b_{i, j}
$$

where $c_{P}[€ / \mathrm{kWh}]$ is the electric power price; $P_{h s}[\mathrm{~kW}]$ and $\eta_{h s}$ are the machine power and the machine power efficiency of the hacksaw; $k_{a m}$ is the factor which considers the allowances to machining time; $T_{c, h s}[\mathrm{~h} / \mathrm{m}]$ is the time for steel cutting and $b_{i, j}[\mathrm{~m}]$ is the overall web width of the truss member.

Edge grinding the steel section:

$$
C_{P, c, g m_{i, j}}=c_{P} \cdot\left(P_{g m} / \eta_{g m}\right) \cdot k_{a m} \cdot T_{g} \cdot l_{g_{i, j}}
$$

where $P_{g m}[\mathrm{~kW}]$ and $\eta_{g m}$ are the machine power and the machine power efficiency of the grinding machine; $T g[\mathrm{~h} / \mathrm{m}]$ is the time of edge grinding and $\lg _{i, j}$ $[\mathrm{m}]$ is the grinding length of the individual truss member.

Shielded metal arc welding, see Creese et al. [10]:

$$
C_{P, w_{i, j}}=c_{P} \cdot \rho_{s} \cdot\left(I \cdot U / \eta_{w}\right) \cdot A_{w_{i, j}} \cdot l_{w_{i, j}} / D R
$$

where $I[\mathrm{kA}]$ and $U[\mathrm{~V}]$ are the welding current and the voltage; $\eta_{w}$ is the machine power efficiency of the arc welding machine and $D R[\mathrm{~kg} / \mathrm{h}]$ is the deposition rate.

Stud arc welding:

$$
C_{P, s w}=c_{P} \cdot\left(I_{s w} \cdot U_{s w} / \eta_{w}\right) \cdot n_{s c} \cdot T_{s w}
$$

where $I_{s w}[\mathrm{kA}], U_{s w}[\mathrm{~V}]$ and $T_{s w}[\mathrm{~h} / \mathrm{stud}]$ are the current, the voltage and the time required for stud welding.

Vibrating the concrete:

$$
C_{P, v}=c_{P} \cdot\left(P_{v} / \eta_{v}\right) \cdot T_{v} \cdot e \cdot L
$$

where $P_{v}[\mathrm{~kW}]$ and $\eta_{v}$ are the power and the machine power efficiency of the concrete vibrator; $T_{v}\left[\mathrm{~h} / \mathrm{m}^{2}\right]$ is the time required for consolidation of the concrete. 


\subsubsection{Labour costs}

Sawing the steel section:

$$
C_{L, c, h s_{i, j}}=c_{L} \cdot k_{a m} \cdot T_{c, h s} \cdot b_{i, j}
$$

where $c_{L}[€ / \mathrm{h}]$ denotes the labour cost per working hour.

Edge grinding of the steel section:

$$
C_{L, g_{i, j}}=c_{L} \cdot k_{a m} \cdot T_{g} \cdot l_{g_{i, j}}
$$

Preparation, assembly and tacking of the steel structure to be welded:

$$
C_{L, p, a, t}=c_{L} \cdot T_{p, a, t}
$$

where $T_{p, a, t}[\mathrm{~h}]$ is the time for the preparation, assembling and tacking.

Manual shielded metal arc welding:

$$
C_{L, S M A W_{i, j}}=c_{L} \cdot k_{d} \cdot k_{w p} \cdot k_{w d} \cdot k_{w l} \cdot k_{r} \cdot T_{S M A W} \cdot l_{w_{i, j}}
$$

where $k_{d}$ is the difficulty factor which reflects the local working conditions; $k_{w p}$ is the factor which considers the welding position; $k_{w d}$ considers the welding direction; $k_{w l}$ considers the shape and the length of the weld; $k_{r}$ considers the chamfering of the root of the weld; $T_{S M A W}[\mathrm{~h} / \mathrm{m}]$ is the time for manual shielded metal arc welding.

Semi-automatic stud arc welding:

$$
C_{L, s w}=c_{L} \cdot T_{s w p} \cdot n_{s c}
$$

where $T_{\text {swp }}[\mathrm{h} / \mathrm{stud}]$ denotes the time needed for stud welding, placing/removal of a ceramic ferrule and cleaning the connection.

Steel surface preparation and protection:

$$
C_{L, s p p_{i, j}}=c_{L} \cdot k_{d p} \cdot\left(T_{s s}+n_{a c} \cdot T_{a c}+n_{f p} \cdot T_{f p}+n_{t c} \cdot T_{t c}\right) \cdot A_{s s_{i, j}}
$$

where $k_{d p}$ is the difficulty factor related to the painting position; $T_{s s}\left[\mathrm{~h} / \mathrm{m}^{2}\right], T_{a c}$ $\left[\mathrm{h} / \mathrm{m}^{2}\right], T_{f p}\left[\mathrm{~h} / \mathrm{m}^{2}\right]$ and $T_{t c}\left[\mathrm{~h} / \mathrm{m}^{2}\right]$ are the times for the sand-spraying, the anticorrosion resistant painting, the fire protection painting and the top coat painting of the steel surface, respectively; $n_{a c}, n_{f p}$ and $n_{t c}$ are the numbers of layers of the anti-corrosion resistant paint, the fire protection paint and the top coat paint.

Placing the formwork (panelling, levelling, disassembly and cleaning):

$$
C_{L, f}=c_{L} \cdot T_{f} \cdot e \cdot L
$$

where $T_{f}\left[\mathrm{~h} / \mathrm{m}^{2}\right]$ represents the time necessary for panelling, levelling, disassembly and cleaning a formwork.

Cutting, placing and connecting the reinforcement:

$$
C_{L, r}=c_{L} \cdot \rho_{s} \cdot k_{r h} \cdot k_{r i} \cdot T_{r} \cdot A_{s} \cdot l_{s} \cdot L
$$

where $k_{r h}$ and $k_{r i}$ are the difficulty factors related to the structural height and inclination of the concrete slab; $T_{r}[\mathrm{~h} / \mathrm{kg}]$ is the time required for the cutting, placing and connecting of the reinforcement.

Concreting the slab:

$$
C_{L, c}=c_{L} \cdot T_{c} \cdot d \cdot e \cdot L
$$

where $T_{c}\left[\mathrm{~h} / \mathrm{m}^{3}\right]$ represents the time for placement of the pumped concrete. 
Concrete consolidation:

$$
C_{L, v}=c_{L} \cdot T_{v} \cdot e \cdot L
$$

Curing the concrete:

$$
C_{L, c c}=c_{L} \cdot T_{c c} \cdot d \cdot e \cdot L
$$

where $T_{c c}\left[\mathrm{~h} / \mathrm{m}^{3}\right]$ is the time required for the curing of the concrete.

For detailed interpretation and the values of the parameters see Reference [5].

\subsection{Structural analysis constraints}

The objective function is subjected to structural analysis constraints defined according to Eurocode 4 for both the ULS and the SLS conditions. The optimization model formulation and structural analysis constraints for the presented composite structure may be found in reference Klanšek et al. [11].

\section{Numerical example}

The paper presents the cost optimization of a $30 \mathrm{~m}$ long simply supported composite truss floor system, subjected to self-weight and the variable load of $3.5 \mathrm{kN} / \mathrm{m}^{2}$, see Figure 2 .

The material, power and labour cost parameters are shown in Table 1. The fabrication times and the approximation functions for the fabrication times are shown in Table 2 and Table 3. All other input data are listed in Table 4.

$$
\mathrm{q}=3.5 \mathrm{kN} / \mathrm{m}^{2}
$$

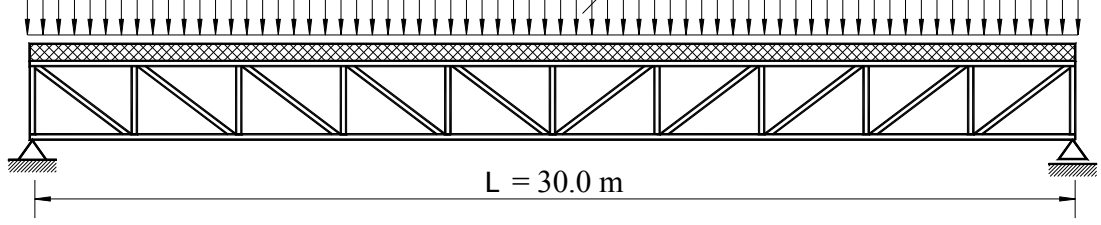

Figure 2: Composite truss system.

Table 1: $\quad$ Material, power and labour costs parameters.

\begin{tabular}{llll}
\hline$c_{M, s}$ & Price of the structural steel S 235-S 355: & $1.00-1.07$ & $€ / \mathrm{kg}$ \\
$c_{M, c}$ & Price of the concrete C 25/30-C 50/60: & $85.00-120.00$ & $€ / \mathrm{m}^{3}$ \\
$c_{M, r}$ & Price of the reinforcing steel S 400: & 0.70 & $€ / \mathrm{kg}$ \\
$c_{M, s c}$ & Price of the cylindrical shear studs: & 0.50 & $€ / \mathrm{piece}$ \\
$c_{M, e}$ & Price of the electrodes: & 1.70 & $€ / \mathrm{kg}$ \\
$c_{M, a c}$ & Price of the anti-corrosion paint: & 0.85 & $€ / \mathrm{m}^{2}$ \\
$c_{M, f p}$ & Price of the fire protection paint (F 30): & 9.00 & $€ / \mathrm{m}^{2}$ \\
$c_{M, t c}$ & Price of top coat paint: & 0.65 & $€ / \mathrm{m}^{2}$ \\
$c_{M, f}$ & Price of the prefabricated floor-slab panels: & 30.00 & $€ / \mathrm{m}^{2}$ \\
$c_{P}$ & Electric power price: & 0.10 & $€ / \mathrm{kWh}$ \\
$c_{L}$ & Labour costs: & 20.00 & $€ / \mathrm{h}$ \\
\hline
\end{tabular}


Table 2: $\quad$ Fabrication times.

$T_{c, h s}$ Time for sawing the steel sections: $1.337 \mathrm{~h} / \mathrm{m}$

$T_{g}$ Time for edge grinding of the steel sections: $33.333 \times 10^{-3} \mathrm{~h} / \mathrm{m}$

$T_{s w}$ Time for stud welding: $2.333 \times 10^{-4} \mathrm{~h} / \mathrm{stud}$

$T_{v}$ Time for consolidation of the concrete: $0.200 \mathrm{~h} / \mathrm{m}^{2}$

$T_{s w p}$ Time for welding/placing/removal of a ferrule/cleaning: $55.555 \times 10^{-4} \mathrm{~h} / \mathrm{stud}$

$T_{s s}$ Time for sand-spraying: $0.050 \mathrm{~h} / \mathrm{m}^{2}$

$T_{a c}$ Time for anti-corrosion resistant painting: $0.050 \mathrm{~h} / \mathrm{m}^{2}$

$T_{f p}$ Time for fire protection painting: $0.050 \mathrm{~h} / \mathrm{m}^{2}$

$T_{t c}$ Time for top coat painting: $0.050 \mathrm{~h} / \mathrm{m}^{2}$

$T_{f}$ Time for panelling/levelling/disassembly/cleaning the formwork: $0.300 \mathrm{~h} / \mathrm{m}^{2}$

$T_{r} \quad$ Time for cutting/placing/connecting the reinforcement: $0.024 \mathrm{~h} / \mathrm{kg}$

$\underline{T_{c c}}$ Time for curing the concrete: $0.200 \mathrm{~h} / \mathrm{m}^{3}$

Table 3: Approximation functions for fabrication times.

$T_{p, a, t}{ }^{*}$ Time for preparation/assembling/tacking: $T_{p, a, t}=C_{1} \cdot \Theta_{d} \cdot\left(\kappa \cdot \rho_{s} \cdot V_{s}\right)^{0.5} / 60[\mathrm{~h}]$; $C_{1}=1.0 \mathrm{~min} / \mathrm{kg}^{0.5} ; \Theta_{d}=3.00 ; \kappa=23$ elements; $\rho_{s}=7850 \mathrm{~kg} / \mathrm{m}^{3}$ and $V_{s}\left[\mathrm{~m}^{3}\right]$

$T_{S M A W}$ Time for manual shielded metal arc welding:

Fillet welds:

$T_{S M A W}=a_{2} \cdot a_{w}^{2}+a_{1} \cdot a_{w}+a_{0}[\mathrm{~h} / \mathrm{m}]$

$a_{2}=1.2653 \times 10^{-2} ; a_{1}=1.3773 \times 10^{-3} ; a_{0}=1.6111 \times 10^{-2}$ and $a_{w}[\mathrm{~mm}]$

$1 / 260^{\circ} \mathrm{V}$ welds:

$T_{S M A W}=b_{6} \cdot a_{w}{ }^{6}+b_{5} \cdot a_{w}{ }^{5}+b_{4} \cdot a_{w}{ }^{4}+b_{3} \cdot a_{w}{ }^{3}+b_{2} \cdot a_{w}{ }^{2}+b_{1} \cdot a_{w}+b_{0}[\mathrm{~h} / \mathrm{m}]$

$b_{6}=-1.7138 \times 10^{-8} ; b_{5}=1.7372 \times 10^{-6} ; b_{4}=-0.5576 \times 10^{-4} ; b_{3}=4.1851 \times 10^{-4}$;

$b_{2}=1.0805 \times 10^{-2} ; b_{1}=-0.7401 \times 10^{-1} ; b_{0}=2.8286 \times 10^{-1}$ and $a_{w}[\mathrm{~mm}]$

$T_{c} \quad$ Time for placement of pumped concrete: $T_{c}=c_{2} \cdot d^{2}+c_{1} \cdot d+c_{0}\left[\mathrm{~h} / \mathrm{m}^{3}\right]$; $c_{2}=2.4000 \times 10^{-3} ; c_{1}=-5.4000 \times 10^{-2} ; c_{0}=9.9500 \times 10^{-1}$ and $d[\mathrm{~cm}]$

${ }^{*}$ Fabrication time proposed by Jármai and Farkas [12].

The optimization was performed in two successive steps. The first step included the NLP optimization, where the continuous variables were calculated inside their upper and lower bounds. At this stage, the structure was fully exploited considering either ultimate or serviceability limit state conditions. In the second step, the calculation was repeated/checked for the fixed variables rounded up, from in the first stage obtained continuous values, to their nearest upper standard values. CONOPT (Generalized reduced-gradient method) was used for the optimization, Drud [13]. The obtained optimal structural design is presented in Figures 3 and 4.

The optimal result of $7329.57 €$ per single composite truss (or $87.26 € / \mathrm{m}^{2}$ of useable floor surface) was obtained in the second NLP stage. The optimal steel sections are listed as follows: top chord (UPE 270) bottom chord (UPE 270); diagonals $D_{1}$ (UPE 160), $D_{2}$ (UPE 140), $D_{3}$ (UPE 120), $D_{4}$ (UPE 100), $D_{5}$ (UPE $100)$; verticals $V_{1}$ (UPE 160), $V_{2}$ (UPE 160), $V_{3}$ (UPE 140), $V_{4}$ (UPE 120), $V_{5}$ (UPE 100), $V_{6}$ (UPE 100). 
Table 4: $\quad$ Input data.

\begin{tabular}{ll}
\hline$\rho_{s}$ & Steel density: $7850 \mathrm{~kg} / \mathrm{m}^{3}$ \\
$\rho_{c}$ & Concrete density: $2500 \mathrm{~kg} / \mathrm{m}^{3}$ \\
$E M Y$ & Electrode metal yield: 0.60 \\
$k_{p}$ & Paint loss factor-painting technique: 0.05 brush painting \\
$k_{s u r}$ & Paint loss factor-complexity of the structure: 1.00 large surfaces \\
$k_{w c}$ & Paint loss factor-weather conditions: 1.00 brush painting \\
$n_{u c}$ & Number, how many times the formwork floor-slab panels may be \\
& used: 30 \\
$k_{a m}$ & Factor-allowances to machining time: 1.09 machining process \\
$P_{h s}$ & Power of the hacksaw: $2.20 \mathrm{~kW}$ \\
$\eta_{h s}$ & Machine power efficiency: 0.85 hacksaw \\
$P_{g m}$ & Power of the grinding machine: $1.10 \mathrm{~kW}$ \\
$\eta_{g m}$ & Machine power efficiency: 0.85 grinding machine \\
$I$ & Welding current: $230 \mathrm{~A}$ \\
$U$ & Welding voltage: $25 \mathrm{~V}$ \\
$\eta_{w}$ & Machine power efficiency: 0.90 arc welding machine \\
$D R$ & Deposition rate: $3.7 \mathrm{~kg} / \mathrm{h}$ \\
$P_{v}$ & $\begin{array}{l}\text { Power of the internal vibrator } \varnothing 48 \mathrm{~mm}: 3.10 \mathrm{~kW} \\
\eta_{v}\end{array}$ \\
$k_{d}$ & Machine power efficiency: 0.85 internal concrete vibrator \\
$k_{w p}$ & Difficulty factor-working conditions: 1.00 normal conditions \\
& Difficulty factor-welding position: 1.00 flat, 1.10 vertical and \\
$k_{w d}$ & Difficulty factor-welding direction: 1.00 flat position and vertical \\
& welds \\
$k_{w l}$ & Difficulty factor-welding length: 1.00 long welds \\
$k_{r}$ & Difficulty factor-root of the weld: 1.00 welds without treatment of \\
& root \\
$k_{d p}$ & Difficulty factor-painting position: 1.00 horizontal painting \\
$k_{r h}$ & Difficulty factor-structural height: 1.00 structural height less than 6 \\
& m \\
$k_{r i}$ & Difficulty factor-inclination of the concrete slab: 1.00 horizontal \\
& slab \\
\hline &
\end{tabular}

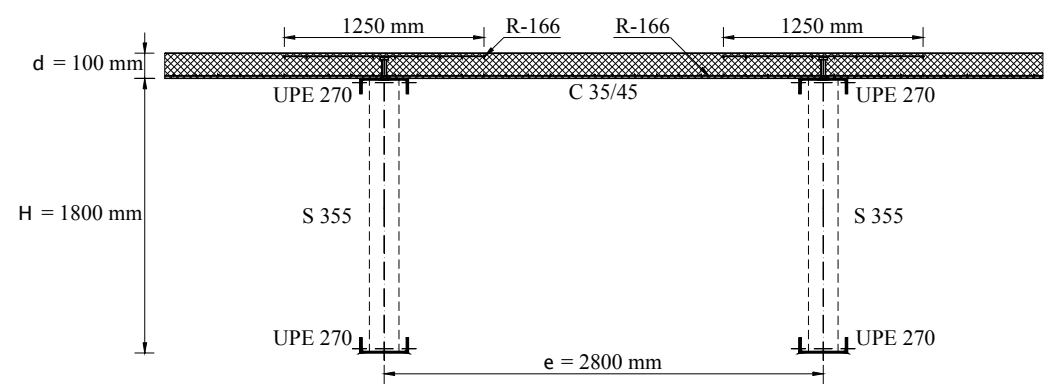

Figure 3: Optimal design of composite trusses. 


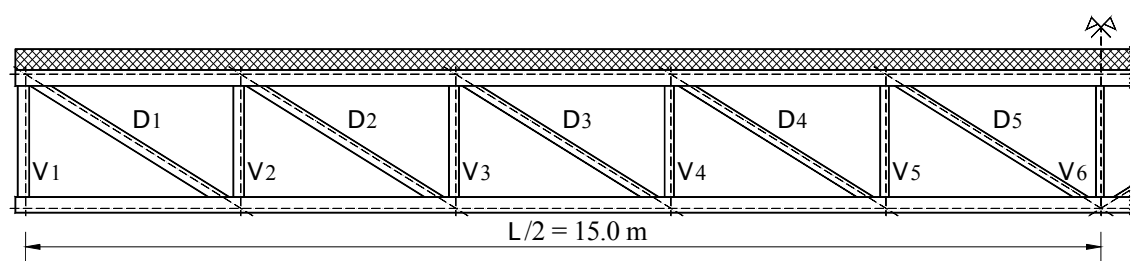

Figure 4: $\quad$ Arrangement of steel truss members.

\section{Conclusions}

The paper presents the cost optimization of composite floor system. The composite structure consists of a reinforced concrete slab and welded steel Pratt trusses built up of hot rolled channel sections. The optimization is performed by the nonlinear programming approach, NLP. A detailed objective function of the manufacturing material, power and labour costs is subjected to structural analysis constraints.

The use of modern optimization techniques essentially improves the economical efficiency of structural design of the composite floor systems.

\section{References}

[1] Surtees J.O. and Tordoff, D., Optimum design of composite box girder bridge structures. Proceedings of the Institution of Civil Engineers (London), Part 1 - Design \& Construction, Vol. 63, No. 2, pp. 181-194, 1977.

[2] Bhatti, M.A., Optimum cost design of partially composite steel beams using LRFD. Engineering Journal, Vol. 33, No. 1, pp. 18-29, 1996.

[3] Cohn, M.Z. and Werner, J.J., Optimization of composite highway bridge systems, Proceedings of the $199612^{\text {th }}$ Conference on Analysis and Computation, pp. 135-146, 1996.

[4] Kravanja, S. and Šilih, S., The MINLP optimization of composite I-beams, Proceedings of the Sixth International Conference on Computer Aided Optimum Design of Structures, Vol. 7, pp. 401-407, 2001.

[5] Klanšek, U. and Kravanja, S., Cost estimation, optimization and competitiveness of different composite floor systems. Part 1, Selfmanufacturing cost estimation of composite and steel structures. Journal of Constructional Steel Research, Vol. 62, No. 5, pp. 434-448, 2006.

[6] Eurocode 1, Basis of design and actions on structures, European Committee for Standardization, Brussels, 1995.

[7] Eurocode 2, Design of concrete structures, European Committee for Standardization, Brussels, 1992.

[8] Eurocode 3, Design of steel structures, European Committee for Standardization, Brussels, 1995.

[9] Eurocode 4, Design of composite structures, European Committee for Standardization, Brussels, 1992. 
118 High Performance Structures and Materials IV

[10] Creese, R.C., Adithan, M. and Pabla, B.S., Estimating and costing for the metal manufacturing industries, New York: Marcel Dekker, 1992.

[11] Klanšek, U., Šilih, S. and Kravanja, S., Cost optimization of composite floor trusses. Steel \& Composite Structures, Vol. 6, No. 5, pp. 435-457, 2006.

[12] Jármai, K. and Farkas J., Cost calculation and optimization of welded steel structures. Journal of Constructional Steel Research, Vol. 50, No.2, pp. 115-135, 1999.

[13] Drud, A.S., CONOPT - A Large-Scale GRG Code, ORSA Journal on Computing, Vol. 6, No. 2, pp. 207-216, 1994. 